\title{
Developing an Instrument to Measure Pedagogical Content Knowledge Using an Action Learning Method
}

\author{
Zulfikar Alimuddin \\ Institut Teknologi Bandung, School of Business Management, Indonesia, \\ zulfikar.alimuddin@sbm-itb.ac.id
}

Jann Hidajat Tjakraatmadja

Prof., Institut Teknologi Bandung, School of Business Management, Indonesia, jannhidajat@sbm-itb.ac.id

\section{Achmad Ghazali}

Dr., Institut Teknologi Bandung, School of Business Management, Indonesia, achmadghazali@sbm-itb.ac.id

Pedagogical content knowledge (PCK) is a category of teachers' knowledge that encompasses knowledge used by teachers to successfully deliver subject materials to students in classroom practice. To examine the extent to which teachers have developed their PCK and how they could improve, they need a tool to measure such a concept. This study, therefore, aimed to provide an instrument which can be used as a reference to measure teachers' PCK from a general perspective. This study constructed an instrument which consists of open-ended questions, exemplary answers and a five-level rubric. The instrument uses action learning and PCK as the foundation concept in its development. The instrument was developed based on Watkins and Marsick's continuous learning model and Morine-Dershimer and Kent's interpretation of PCK. Validation of the instrument content was conducted by experts in the education field. Test-retest reliability was carried out to examine the reliability. A Wilcoxon signed-ranking analysis indicated that pretest and post-test answers to the questions show no significant differences, which indicates that the instrument is reliable for use.

Keywords: instrument, pedagogical content knowledge, action learning, Watkins and Marsick's continuous learning model, rubric

\section{INTRODUCTION}

Pedagogical content knowledge (PCK) is known as the knowledge needed by teachers to have adequate teaching practice (Carlsen, 1999; Morine-Dershimer \& Kent, 1999; 
Shulman, 1986). Teachers are encouraged to improve their teaching quality by improving their PCK (OECD, 2014). The appeal to improve PCK can be seen in educational articles, academic journals, mandates or educational bodies' decrees and recommendations. To be able to improve, one should first know how to assess teachers' current PCK. Meanwhile, a practical tool to assess teachers' PCK is still lacking and in need of innovation. From the school management perspective, a tool that is able to measure teachers' PCK regardless of their subject area would be an effective measuring tool. Such an instrument could be used to analyze teachers' PCK and inform schools about what kind of supports they could offer for teachers to improve their PCK.

Reports concerning instruments that could be used to measure teachers' PCK in general (instead of subject specific) are limited. Few people are familiar with the PCK concept in order to develop it. Search results from Education Resources Information Center (ERIC) database for 'Pedagogical Content Knowledge' in October 2018 yielded 6,851 results, ranging from 1999 to 2018. This number is far less compared to a search for 'Content Knowledge', which yielded 24,987 results (with only 5,636 discussing PCK as well). Among those articles, there are fewer studies on creating an instrument to measure PCK. A search result of the ERIC database for 'Pedagogical Content Knowledge' AND 'Instrument' in October 2018 yielded 344 results, ranging from 1999 to 2018. These studies tend to discuss creation of a PCK instrument specific to certain subject knowledge (Abdullah \& Halim, 2010; Jin, Shin, Johnson, Kim \& Anderson, 2015; Jüttner \& Neuhaus, 2012; Kratz \& Schaal, 2015). Meanwhile, no study has created a single instrument capable of measuring teachers' PCK that can be used for teachers from all subject areas.

The reason for creating a subject-specific PCK instrument could be based on the early development of PCK. Shulman $(1987,1986)$ often provided illustrations to introduce readers to the concept of PCK in action. Such illustrations are contextual and limited to single subject matter only. However, most articles that discussed the creation of an instrument rarely discuss the reason why a certain subject was chosen as the context in which to create a PCK assessment tool.

The main drawback of the creation of a subject-specific PCK assessment tool is that all of these tools use different parameters and indicators to measure teachers' PCK. From a school management perspective, it makes it difficult for schools to assess all teachers' PCK quality in a fair way. For example, Abdullah and Halim (2010) created an assessment tool to measure environmental teachers' PCK quality. They used their own PCK conceptualisation, which combines many perspectives of PCK as the underlying theory behind their assessment tool. There are 87 questions that they created to measure teachers' PCK, based on five PCK aspects. On the other hand, Jüttner and Neuhaus (2012) created 24 questions to measure biology teachers' PCK, which used a different scoring system and underlying knowledge. Such differences could also be seen in Jin et al. (2015), Kratz and Schaal (2015) and other subject-specific PCK assessment tools.

Another important reason not to use a subject-specific instrument is because it is subject specific in its construct. For example, a question in Kratz and Schaal (2015), who created a PCK assessment tool for science teachers, asked the teachers about which 
context is more suitable to deliver the subject of equalisation of air: a) delivering pizza using a Styrofoam box; or b) hairdryer air flow. These questions are too strictly applied to the science subject, especially physics, so they cannot be used to check PCK from, for example, social subjects such as economy.

The researchers however, wanted to create an instrument to measure PCK that could be used to measure teachers' PCK in a fair way and which could be used across all subjects. This instrument was created as a part of a bigger research project to improve teachers' PCK who work in the same school. One instrument that could evaluate all teachers' PCK from the same theoretical foundation and perspective could help the school to analyse and understand the most common shortcomings of teachers' teaching practice from a PCK perspective. This information could be used to provide teachers with a supportive environment to improve their PCK.

Although, in the past, most assessment tools for PCK were created for specific subjects, this article wants to shows that it is possible to create an instrument that is not limited to one subject only and could be used by all teachers from different subjects. In this article, the researchers consider that PCK is not only mainly comprised of content knowledge, but also many other knowledge aspects that are shared by teachers who work in the same environment, such as the education system that supports the educational activities in the school, curriculum, students' characteristics, etc. These knowledge aspects will be explained separately in this article.

Based on the explanation above, this article will discuss how to create an instrument that could measure teachers' PCK across all subjects.

\section{THEORETICAL BACKGROUND OF THE INSTRUMENT'S FRAMEWORK}

In terms of creating an assessment, the researchers reflect on students' learning assessments and the use of Bloom's Taxonomy of Cognitive Domain (Bloom, 1956). There are six steps of acquiring knowledge according to this taxonomy: from understanding (first/lowest level of cognitive learning) to evaluating (highest level of learning). The taxonomy has been used widely in the education field, especially for teaching in formal schools from elementary to senior high school (Forehand, 2005). It has been very useful to help teachers with tracing students' cognitive knowledge and using that knowledge to determine what steps should be taken to in order to facilitate their learning experience (Airasian \& Miranda, 2010).

However, unlike students, teachers in schools are adults. The theory of learning suggests that adults have a different theory of learning. Two theories that are often to referred to when discussing adult learning are experiential learning and transformative learning (Roessger 2012; Tusting \& Barton, 2003). As the name suggests, experiential learning requires engagement of adult learners with experience. According to Beard and Wilson (2013), experiential learning is 'the sense-making process of active engagement between the inner world of the person and the outer world of the environment'. When learning occurs, learners will always contest between their previous knowledge and the experience at hand. As a consequence of this view, the focus of learning is on the process rather than the outcome. 
A similar perspective could also be found in the concept of transformative learning, called reflection. Transformative learning further specifies on the importance of this process (Tusting \& Barton, 2003). Mezirow (1997) views reflection as the process whereby a person can change the way they see a situation/problem. The goal of transformative learning is for the person to be an autonomous thinker. Someone who has gone through transformative learning would be able to detect their own limitations through reflection and use a changing perspective to try to solve a problem when a solution is needed. These theories set a certain path to create an instrument that can help teachers to assess and trace their level of learning in the understanding and practice of PCK.

Reflecting on all of the above arguments, the researchers decided to create an instrument that adhered to the above understanding of adult learning to assess teachers' PCK.

\section{LITERATURE REVIEW}

\section{Pedagogical Content Knowledge}

PCK was first introduced by Shulman in 1986 in his paper pertaining to teachers' knowledge. Compared to other teachers' knowledge that he listed in the paper, PCK holds more importance. PCK is the type of teachers' knowledge that combines both teachers' mastery of content and pedagogical knowledge (Shulman, 1986). To have PCK means that a teacher knows the content that is most representative of that subject, while, at the same time, also knowing the best way to teach it.

More research and development on PCK resulted in more insight about the subject. Morine-Dershimer and Kent (1999) discovered that PCK is encompassed by more knowledge related to educational practice. The summary of their interpretation of PCK, along with other knowledge types that are involved can be seen in Figure 1.

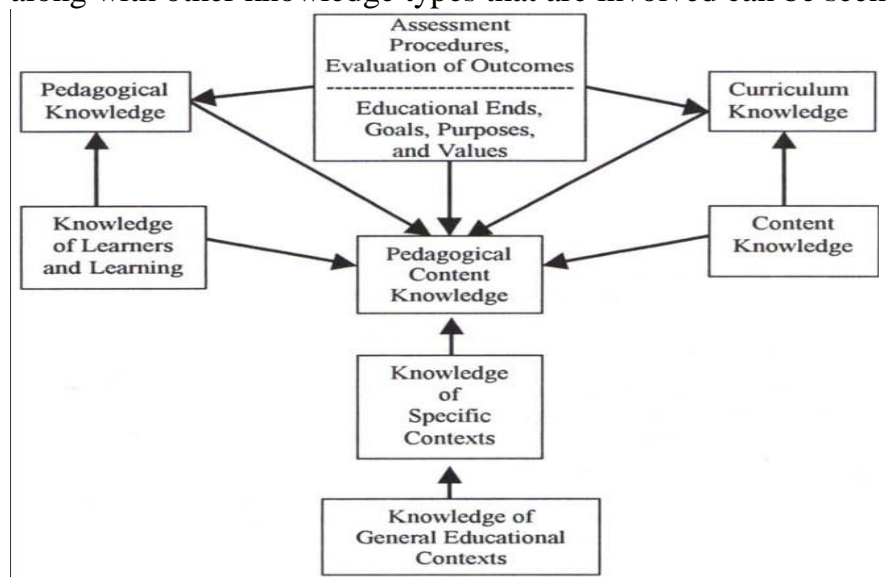

Figure 1

Interpretation of PCK by Morine-Dershimer and Kent (1999) 
Pedagogical knowledge refers to general knowledge about teaching, such as instructions in the classroom or the teaching model used in class. This also includes the various theories about learning that teachers acquire during teacher training or after teaching for a period of time. Content knowledge is knowledge about the subject matter from an academic perspective. This is the knowledge that is to be taught in the classroom. Content knowledge refers to the breadth and depth of the knowledge, regardless of whether it will be taught in the classroom or not. Shulman (1986) proposed that PCK is the result of a combination of both. However, a few years after PCK was introduced to the public, Morine-Dershimer and Kent (1999) argued that there are other knowledge types that need to be recognized to optimize PCK quality; hence, they came up with the development as shown in figure 1 . They argued that such development was necessary because PCK is much more complex when applied in the classroom. This model is the next step that should be taken considering the education world now have more understanding about PCK.

According to Morine-Dershimer and Kent (1999), there are seven knowledge types that encompass PCK including pedagogical knowledge, content knowledge, curriculum knowledge, knowledge of learner and learning, assessment and goals (specifically assessment procedures, evaluation outcomes unseparated from educational ends, goals, purposes and values), knowledge of specific contexts and knowledge of the general educational context.

Each of these knowledge types are related differently to one another while also being directly related to PCK. For example, teachers' pedagogical knowledge is affected by teachers' knowledge about educational goals and evaluation. Meanwhile, content knowledge is independent knowledge, which would affect teachers' understanding of the curriculum. The model also shows that knowledge types that constructed PCK could be related to one another. When discussing a certain knowledge type, the discussion would intersect the domain of another knowledge. These relationship between knowledge types can be seen more in Figure 1. Understanding this relationship is integral to understanding various possible conversations regarding PCK.

Overall, according to the interpretation above, PCK demands teachers to have various knowledge types from within their working environment and be able to acquire as much information as possible. By stating the various knowledge types needed to construct PCK, the above interpretation could also help teachers to identify which knowledge type they are lacking. Even though other attempts have also been made by other experts to develop Shulman's PCK work further - such as models created by Carlsen (1999), Gess-Newsome (1999), Grossman (1990) or Magnusson, Krajcik and Borko (1999) none of these are quite as comprehensive in addressing specific knowledge as MorineDershimer and Kents' interpretation (1999). Furthermore, other developments of the PCK definition by other experts tend to use the same terminologies while referring to different meaning. It makes understanding which is which a more complex task. For the above reason, this article chooses to use Morine-Dershimer's interpretation of PCK as the underlying PCK concept for the instrument; it is the PCK that could be helpful to aid teachers to recognize aspects of their teaching and improve them. 
Improving PCK means improving teaching quality. Teachers are encouraged to improve their PCK as seen in educational articles, academic journals, mandates or educational bodies' decrees and recommendations (Harr, Eichler \& Enkl, 2014; OECD, 2014). However, an assessment tool is needed to measure teachers' current PCK before one starts to consider improving it. Unfortunately, literature focusing on assessing teachers' PCK is still limited. Most research and reports within the domain of PCK often only discuss certain PCK components or subject-specific PCK, rather than a general approach to assess PCK as a whole (Abdullah \& Halim, 2010; Jin et al., 2015; Jüttner et al., 2012; Kratz \& Schaal, 2015).

\section{Reflection and Watkins and Marsick's Continuous Learning Model}

As explained in the introduction, the theory of adult learning has created a broad sense of direction in creating a tool for assessing teachers' PCK. Both theories of adult learning, experiential learning and transformative learning, highlight the importance of learning from experience and reflection, so that the adult could be an autonomous thinker (Kolb, 1984; Mezirow, 1997; Tusting \& Barton, 2003). Since teaching is a profession where teachers need to be able to make decisions (both in planning and infield quick decisions), this skill is vastly important.

When an individual is reflecting on their experience, they are expected to think and analyse their past experiences and actions with the aim of analyzing and learning from them (Atkins \& Murphy, 1993; Boud, 1993). According to Mezirow (1997), being reflective could help a person to be more conscious of what they have done and the reasons for their actions. This also opens the possibility for them to recognise their point of view when a problem occurs, and reconsider other points of view so that the problem can be solved.

Being reflective has also been known to be necessary for teachers so that they can improve their practice (Jay \& Johnson, 2002; Smyth, 1989). When teachers were asked to be reflective by doing self-assessment of their practice, they claimed that they gain deeper insight into strengths and weaknesses of their teaching practice (Ratminingsih, Artini \& Padmadewi, 2017). Reflection leads teachers to be critical of their past practice and habits, which might have impeded or supported students' learning. One of a few frameworks that could assist teachers to reflect is action learning.

Action learning is a learning framework introduced by Revans (1982). Participants of action learning are encouraged to solve their work problems by reflecting on their past practice and observing their professional peers in action. This knowledge would be evaluated and used to solve the problem and avoid its future occurrence (Revans, 1982). Action learning uses experience as a learning context, which makes it easier for learners to learn new knowledge (Griffiths \& Guile, 2001).

Action learning guides the reflection process through the following six fundamental questions:

1. What am I (or what is my firm) really trying to do, first and last?

2. What is stopping me (or my firm) from doing it?

3. What can I (or my firm) contrive about it? 
4. Who knows what the line of action that we are trying to implement is?

5. Who cares about getting this line of action really implemented?

6. Who can actually contribute anything towards getting it implemented?

Action learning has been known to be a good framework to help employees to reflect in their work as shown by Rosser (2016), Christiansen et al. (2014), and O'Donoghue (2011). However, the six questions are still rather generic for application directly as a measurement framework, especially when it is to be used to measure multiple employees. Besides, Revans also claimed that these questions were intended as a guideline for conducting action learning rather than a step-by-step procedure for practice (Brook, Pedler \& Burgoyne, 2012; Dilworth, 2010).

Over time, the concept of action learning has developed into action learning models so that it would be easier to implement action learning in a corporation setting (Brix, 1983). For the purpose of creating an assessment tool, a model that thoroughly incorporates action learning steps and is convenient to implement is needed. One model that could meet this requirement is Watkins and Marsick's Continuous Learning Model (WMCLM).

Chenhall and Chermack (2010) made a list of models rooted in the action learning concept. There are four models of action learning that were developed by several experts after the introduction of action learning by Revans. These are the action learning group model, Systemic Action Learning Cycle (SALC) model, Systemic Action Learning Spiral, Watkins and Marsick Continuous Learning Model. Among these models, the researchers found that Watkins and Marsick's Continuous Learning Model is superior and more compatible for teachers' working environments. Compared to other models, the WMCLM is superior because it has a double loop learning process.

The double loop learning process in the WMCLM encourages participants to have two paths during the thinking process. Figure 2 could help to understand double loop thinking:

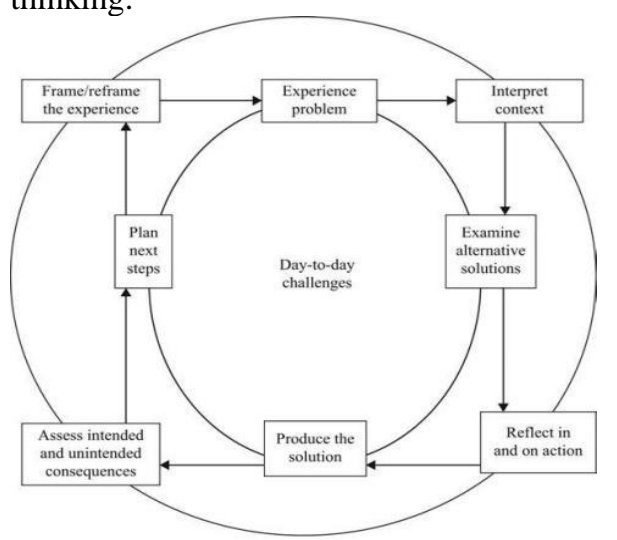

Figure 2

WMCLM Model (Watkins and Marsick, 1993) 
There are 8 steps that should be followed in WMCLM. There are two circle that connected those questions. 8 Steps and both circles surround the middle part of the model. The center of the model represents the problem, a context that would be focused on during action learning process. In this case, it is the day to day challenges that the participant face in their work. The inner loop represents the simple step of problemsolving. Meanwhile the outer loop represents reflection process. The outer loop shows a deeper level of the problem-solving process when someone chooses to reflect critically on the presented problem. Thinking through the outer loop during learning process helps people to see the problem that they might not previously realize because it addresses thinking the process that people often skips (as demonstrated in the inner loop) since it usually happens within the unconscious mind.

By explicitly stating the learning steps, the model leads adult learners to reflect on their practice and their assumptions. It forces them to consider different perspectives as they review their past practice. Meanwhile, the outer loop process assists participants in improving their sensitivity to the situation and occurring problems, so that they could prevent their future occurrence (Watkins \& Marsick, 1992). Such a thinking path is not explicitly addressed in the other three models. The WMCLM is more fitting as a guide for the thinking process, as it arranges and addresses what explicitly needs to be done so that both the problem-solving and the reflection process can occur alongside one another.

The WMCLM is a right fit for PCK due to the way in which PCK is developed. PCK is practice based knowledge (Gess-Newsome et al., 2019), where its improvement depends on a teacher's mastery of teaching practice in class, while the WMCLM is a method to reflect on experience. The double loop thinking process in the WMCLM provides teachers with a path that encourages them to make their teaching problem the centre of their thinking process (Watkins \& Marsick, 1993). Teachers are facilitated to trace back their thinking process as they face problems in their class: a situation where their PCK is needed to handle it. They would review the problem and explore many possible ways to solve it by consulting the various knowledge types in PCK. Hence, the WMCLM is a fitting model to facilitate teachers to reflect on their teaching experiences and demonstrate what improvements could be made.

\section{CREATING THE INSTRUMENT: BUILDING A CONCEPTUAL MODEL WHICH LINKS THE WMCLM AND PCK}

The clear process of the WMCLM opens an opportunity for the researchers to get the benefits of the action learning concept through implementation of the WMCLM steps to measure PCK. The WMCLM helps the researchers to determine the various stages in learning the participants' experience. PCK is the knowledge that is visible through implementation. However, it would not be efficient to measure their PCK directly in their classroom, as it would require many assessors to be involved. Hence, the WMCLM steps are used as a tool that could help teachers demonstrate their PCK knowledge through sets of questions that are created by referring to PCK concepts and the WMCLM steps. Teachers are expected to reflect on their teaching experience in the classroom and adjust it accordingly, as guided by the WMCLM components in the 
questions by answering these questions in written form. It is as if the teachers are in the classroom and practicing their PCK, only now they are not in the classroom and their PCK is well documented in a series of written answers to the WMCLM questions. It is through this documented knowledge that the assessor could assess teachers' PCK efficiently. Since PCK is a form of knowledge, it is possible to examine people's knowledge through their written answers (National Research Council, 2001; Povozhaev, 2014). Figure 3 illustrates the theoretical framework of combining the WMCLM and PCK.

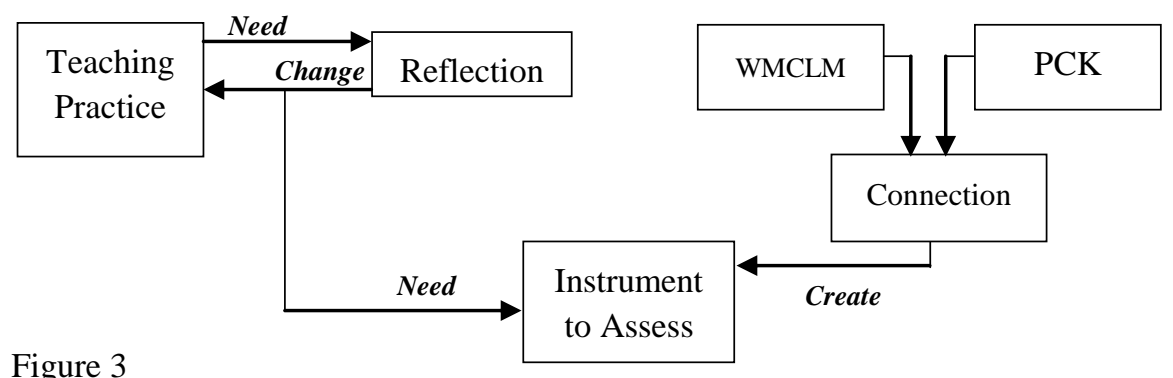

Theoretical base of the WMCLM and PCK Combination

\section{INSTRUMENT DEVELOPMENT AND VALIDATION}

There are two important steps in creating an instrument to assess teachers' PCK. The first is the process of creating the instrument and the second is to check the reliability of the instrument. For the first step, we created an instrument that conforms to the arguments above. For the second step, we ran a reliability test called test-retest reliability (Fraenkel, Wallen \& Hyun, 2012). Further discussion about both methods is outlined separately in the following section.

Creating the Instruments' Question Items: Using the WMCLM as the Framework of the Instrument to Measure PCK

This study generated questions based on critically evaluating and analyzing literature about PCK and the WMCLM, as well as reflecting on teachers' teaching experience. After that, the researchers created question items for the instrument by referring to the WMCLM model and Morine-Dershimer and Kent's PCK model. The researchers created the instrument by combining both concepts and the process of combing is explained in five steps, which are elaborated below.

Step 1. The first step to develop the instrument involved looking at the WMCLM concept and deciding what thinking process should be the starting point. The WMCLM is the thinking process that teachers would experience as they think about PCK. Hence, it is important to decide which thinking process teachers should engage first in thinking about PCK.

This study chose frame-reframe experience as the first step in thinking about PCK. The frame-reframe process can encourage participants to re-examine and recognize their 
current teaching practices for later re-examination. By framing their experience as a whole, they should be able to follow the next step, i.e. to realize the problem that emerged as they carefully re-examined their whole practice. This means that the second step is experiencing the problem and so on.

Table 1

WMCLM steps used to create the instrument

\begin{tabular}{cl}
\hline No & \\
\hline 1 & Frame-reframe the experience \\
2 & Experience problem \\
3 & Interpret context \\
4 & Examine alternative solution \\
5 & Reflect in and on action \\
6 & Produce solution \\
7 & Assess intended and unintended consequences \\
8 & Plan next step \\
\hline
\end{tabular}

Step 2. Combining the WMCLM concept with PCK. To combine both concepts, the researchers made connections between the WMCLM and the knowledge that encompasses PCK. At the same time, the researchers also constructed questions for the instrument that could facilitate teachers to demonstrate their PCK. To create these questions, one of the researchers held brainstorming sessions with teachers from different subjects to discuss their issues in teaching and PCK. Each question was developed according to the WMCLM steps while guiding teachers to externalize their PCK. Each question demanded teachers to address all aspects of PCK from MorineDershimer and Kent's model. To complete the instrument, the researchers also created an example answer for each question.

The researchers examined the seven knowledge types that construct PCK as proposed by Morine-Dershimer and Kent (1999) to observe teachers' PCK. These are pedagogical knowledge, content knowledge, curriculum knowledge, knowledge of learner and learning, assessment and goals (specifically assessment procedure, evaluation outcomes unseparated from educational ends, goals, purposes and values), knowledge of specific contexts and knowledge of general educational context.

The following definitions were adapted based on Shulman (1986, 1987) and MorineDershimer and Kent (1999). These definitions were discussed during brainstorming sessions and used to construct the questions and example answers for the instrument.

- Content knowledge is knowledge about the subject matter that needs to be taught. For example, knowledge that an expert chemist should know about chemistry (Baxter \& Lederman, 1999). Content knowledge that teachers have should be wide and deep, since they are going to teach it to students. Through this knowledge, they should be able to teach comprehensively about the information that is needed in the classroom or address the students' problems with the subject (e.g. misconceptions).

- Pedagogical knowledge is knowledge about teaching. This is the knowledge that teachers could have through teaching experience and learning about teaching theories and various strategies that teachers could use to teach students. 
- $\quad$ Curriculum knowledge refers to the knowledge that is related to arranging the content of the subject matter that is taught in school. This includes knowledge of the curriculum, which is given by the national education ministry to teachers designing the curriculum.

- $\quad$ Knowledge of the learner and learning could be seen as two sides of the same coin. Knowledge of the learner is knowledge about the learning participants. This knowledge is quite wide, ranging from knowledge about a learner's level of understanding (that could be obtained through assessment, for example) to knowledge about students' social backgrounds so that a teacher could choose a fitting context to be brought to class. Meanwhile, knowledge about learning is about the many learning processes the students could experience, such as learning style, learning models and Bloom's taxonomy.

- Knowledge regarding assessment and goals is specified as assessment procedures, evaluation outcomes, educational ends, goals, purposes and values. Assessment procedures are comprised of knowledge on how assessments should be done, what kind of assessments that should be run and all aspects of assessments required in classroom education. Evaluation outcomes are the knowledge regarding how the evaluation is to be used afterwards, such as for revising the curriculum or for students' benefit (high-stakes testing). Educational ends, goals, purposes and values are the knowledge regarding the various aspects that education is expected to contribute, from classroom scale (e.g. students' understanding of content knowledge) to national or even worldwide scale (e.g. national education goals).

- Knowledge of specific contexts refers to knowledge about certain contextual knowledge that could aid students in making relationships between content knowledge (theories) and their own experience.

- $\quad$ And the last knowledge, which is not directly related to PCK, is knowledge of the general educational context. This is the knowledge of general information that supports and has become the environment where education takes place. Included in this category are knowledge about classroom situation, school management, budget, national philosophy, etc.

After the brainstorming sessions, the researchers constructed a question for each of the WMCLM's steps that could facilitate teachers to demonstrate their PCK. Teachers' PCK was observed through their use of the knowledge above (separately or combined) to answer those questions. The researchers also created examples of answers based on the questions. Both questions and answers were then validated by experts in education.

Table 2 shows question items for the instrument and the underlying concepts that construct each question (WMCLM and PCK). Five out of eight questions were related to all knowledge that constructs PCK. By answering these questions, teachers had the opportunity to demonstrate their PCK from many perspectives. These types of questions facilitated teachers to answer the question using essay-like answers, which open opportunities for them to demonstrate PCK as an interconnected knowledge instead of explaining each knowledge separately. 
Table 2

Construct of Each Question According to WMCLM Steps and PCK Concept

\begin{tabular}{|c|c|c|c|}
\hline No & WMCLM step & PCK & Question \\
\hline 1 & $\begin{array}{l}\text { Frame-reframe the } \\
\text { experience }\end{array}$ & $\begin{array}{l}\text { Knowledge of specific } \\
\text { context }\end{array}$ & $\begin{array}{l}\text { What is the context that you often use to deliver your } \\
\text { subject matter? }\end{array}$ \\
\hline 2 & Experience problem & All PCK components & $\begin{array}{l}\text { What are the problems that you usually face during } \\
\text { teaching? }\end{array}$ \\
\hline 3 & Interpret context & $\begin{array}{l}\text { Educational ends, goals, } \\
\text { purposes, values; content } \\
\text { knowledge; knowledge of } \\
\text { specific contexts }\end{array}$ & $\begin{array}{l}\text { Could you interpret the context that you use in your } \\
\text { teaching practice? Explain. }\end{array}$ \\
\hline 4 & $\begin{array}{l}\text { Examine alternative } \\
\text { solutions }\end{array}$ & All PCK components & $\begin{array}{l}\text { What are the considerations when you brought a new } \\
\text { perspective on that subject matter? }\end{array}$ \\
\hline 5 & $\begin{array}{l}\text { Reflect in and on } \\
\text { action }\end{array}$ & All PCK components & $\begin{array}{l}\text { What is the condition or situation that has helped or } \\
\text { impeded you during your teaching practice? }\end{array}$ \\
\hline 6 & Produce solution & All PCK components & $\begin{array}{l}\text { What are the instructions that you gave to deliver } \\
\text { your teaching? }\end{array}$ \\
\hline 7 & $\begin{array}{l}\text { Assess intended and } \\
\text { unintended } \\
\text { consequences }\end{array}$ & $\begin{array}{l}\text { Assessments, procedures } \\
\text { and evaluation of } \\
\text { outcomes }\end{array}$ & $\begin{array}{l}\text { How do you know the success/failure of your } \\
\text { teaching practice? }\end{array}$ \\
\hline 8 & Plan next step & All PCK components & $\begin{array}{l}\text { What are the successes or failures that you have } \\
\text { found in that teaching practice? Moreover, what did } \\
\text { you/would you do when failure occurred/occurs? }\end{array}$ \\
\hline
\end{tabular}

From eight questions, there were three questions that show the close connection between PCK and the WMCLM, as made by the researcher, namely questions 1, 3 and 7. This emphasizes the compatibility of the WMCLM and the PCK concept, where both discuss similar concepts that exist between the WMCLM and PCK.

Question 1 represents the first step of the WMCLM, namely the 'frame-reframe experience'. This WMCLM step is connected with knowledge of specific contexts from Morine-Dershimer and Kent's PCK interpretation. As shown in the WMCLM model in Figure 1, the middle part of the WMCLM pinpoints the 'day-to-day challenge' in action learning as the context in the action learning process. The term context refers to specific and, most often, real life situations. Meanwhile, during practice, teachers should also use an adequate context so that they can introduce and teach students the content knowledge/learning subject from real life examples. The challenge for teachers is the context that they brought to the classroom, whether it is appropriate from a PCK perspective. Based on this connection, the question was designed for teachers to demonstrate their understanding of the context that they will bring to the classroom and will be the context of their action learning process.

Question 3 represents the 'interpret context' of the WMCLM. This step is connected with 'knowledge of educational ends, goals, purposes and values', while at the same time demanding teachers to consult their 'content knowledge and knowledge of specific contexts'. Interpreting context demands WMCLM participants to describe their working context from their current understanding. In relation to PCK, teachers are expected to be able to interpret their 'content knowledge and knowledge of specific contexts' respective to 'educational ends, goals, purposes and values'. The connection is more 
specifically related to the values. Values is the general idea or perspective from a content that want to be taught.

In this question, teachers were asked to interpret the context by understanding the general concept within specific content. An example of this would be:

Content: Cell transport system.

Context: Diffusion on the membrane cells.

General concept to be taught from this content: Selective filtering.

Interpretation: An explanation of the diffusion process that could be understood by the students.

Teachers who could interpret their context correctly must be able to demonstrate the underlying value of the content that they teach.

Question 7 represents 'assess intended and unintended consequences. This step is connected to knowledge of 'assessment procedures and evaluation of outcomes. Both aspects expect participants to make an assessment. In the WMCLM, assessment is made to the context in focus; in PCK, assessment is made based on the context taught to the students. This question asks teachers to evaluate their teaching practice by assessing their students' knowledge.

Step 4. Developing a rubric and scoring system to assess teachers' answers. The rubric has five categories and each category corresponds to the scoring system for the answer. The rubric provides guides for the assessor to determine whether all aspects of PCK that are related to the questions have been considered by the teachers. This is to ensure that the assessor can give an appropriate score for the various answers given by the participants (Stevens \& Levi, 2005). The benefit of using a rubric is that it could be used to measure the answers created from a complex thinking process (Anderson, 1998; Stevens \& Levi, 2005). As demonstrated, PCK has quite a dense structure. Teachers need to have the freedom to externalize it in the form of writing. It is not possible to observe PCK generally if using other forms of assessment such as multiple-choice tests. In multiple answer questions, questions tend to encourage rote learning of information, more directed toward a specific context and only have one right answer. This is not an ideal situation to find out about teachers' PCK if the instrument created is for universal use.

The scoring system used for this instrument is similar to a Likert scale but with different numerical values. Instead of using the $1-5$ or $0-4$ range, this research uses the $0-1$ range with 0.25 intervals. This system is chosen based on the idea that one represents holistic mastery of PCK (score value $=1$ ). Meanwhile, any answer that demonstrates a lack of understanding of PCK would be scored lower than one, with zero as the lowest score.

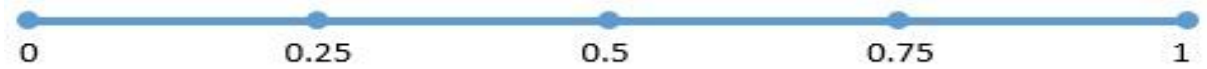

Figure 4

Rubric scoring system 
The researchers also created an example of a perfect answer for each question to accompany the rubric. The questions, rubric and examples of answers were validated by two experts from the education field. The experts' final assessment confirmed that the instrument is valid and ready to be used for pilot testing.

\section{RELIABILITY TEST}

The reliability test for this research involved test-retest reliability (Fraenkel et al., 2012), where the participants were given the test twice within a ten-day span. This reliability test sought to determine whether the test still gives the same results if answered by the same participants after a certain time span. The initial test is called a pretest and the second test (retest) is called post-test.

The participants were 20 teachers who taught different subjects. They teach one natural science subject or social science subject. All of the teachers worked in the same school. The teachers were chosen based on the age group of 20-30 years old. The test was given twice in the school where they teach. The post-test was given ten days after the pretest. The test consisted of eight questions as formulated above, which had to be finished in one sitting, maximum of 120 minutes.

The results of both tests were recorded and then analysed using Wilcoxon signed-rank analysis. This test was used because: 1) the experiment was to compare two groups that are a paired group (pretest and post-test);2) the dependent variable involved ordinal data. With these data, the assumption of other types of reliability test, such as a paired ttest or chi-square test cannot be met. Regarding sample size, it has been shown that the Wilcoxon test could be conducted with samples as small as 12, as shown in Corder and Foreman (2009).

Table 3

Wilcoxon-Signed Ranking Test Result

\begin{tabular}{|c|c|c|c|c|c|c|c|c|c|}
\hline & \multicolumn{7}{|c|}{ Ranks based on pretest and postest result } & \multicolumn{2}{|c|}{$\begin{array}{l}\text { Wilcoxon-signed } \\
\text { ranks test }\end{array}$} \\
\hline & $\begin{array}{l}\text { Nega- } \\
\text { tive } \\
\text { Ranks }\end{array}$ & $\begin{array}{c}\text { Mean } \\
\text { rank }\end{array}$ & $\begin{array}{l}\text { Sum } \\
\text { ranks }\end{array}$ & $\begin{array}{l}\text { Positi } \\
\text { ve } \\
\text { Ranks }\end{array}$ & $\begin{array}{l}\text { Mean } \\
\text { ranks }\end{array}$ & $\begin{array}{c}\text { Sum } \\
\text { ranks }\end{array}$ & Ties & $\mathrm{Z}$ & $\begin{array}{l}\text { Asymp. Sig. } \\
\text { (2-tailed) or } \\
\text { P value }\end{array}$ \\
\hline po1 - pr1 & $1^{\mathrm{a}}$ & 1.50 & 1.50 & $1^{\mathrm{b}}$ & 1.50 & 1.50 & $18^{\mathrm{c}}$ & $.000^{\mathrm{y}}$ & 1.000 \\
\hline po2 - pr2 & $4^{\mathrm{d}}$ & 4.38 & 17.50 & $3^{\mathrm{e}}$ & 3.50 & 10.50 & $13^{\mathrm{f}}$ & $-.632^{\mathrm{z}}$ & .527 \\
\hline po3 - pr3 & $1^{\mathrm{g}}$ & 1.50 & 1.50 & $1^{\mathrm{h}}$ & 1.50 & 1.50 & $18^{i}$ & $.000^{\mathrm{y}}$ & 1.000 \\
\hline po4 - pr4 & $6^{j}$ & 5.50 & 33.00 & $3^{\mathrm{k}}$ & 4.00 & 12.00 & $11^{1}$ & $-1.311^{\mathrm{z}}$ & .190 \\
\hline po5-pr5 & $4^{\mathrm{m}}$ & 4.00 & 16.00 & $6^{\mathrm{n}}$ & 6.50 & 39.00 & $10^{\circ}$ & $-1.221^{\mathrm{aa}}$ & .222 \\
\hline po6 - pr6 & $0^{\mathrm{p}}$ & 0.00 & 0.00 & $6^{q}$ & 3.50 & 21.00 & $14^{\mathrm{r}}$ & $-2.232^{\mathrm{aa}}$ & .026 \\
\hline po7 - pr7 & $4^{\mathrm{s}}$ & 3.00 & 12.00 & $1^{\mathrm{t}}$ & 3.00 & 3.00 & $15^{\mathrm{u}}$ & $-1.342^{\mathrm{z}}$ & .180 \\
\hline po8 - pr8 & $3^{v}$ & 3.67 & 11.00 & $2^{w}$ & 2.00 & 4.00 & $15^{\mathrm{x}}$ & $-.966^{\mathrm{c}}$ & .334 \\
\hline a. pol $<$ pr1 & & g. po3<pr3 & m. p & $<\operatorname{pr} 5$ & s. po7 & & y. The & $\mathrm{m}$ of negat & ve ranks \\
\hline b. pol $>$ pr 1 & & h. po3 > pr3 & n. $\mathrm{pc}$ & pr5 & t. po7 & & equals & e sum of & positive \\
\hline c. $p o 1=\operatorname{pr} 1$ & & i. $p o 3=p r 3$ & o. p & $=\mathrm{pr} 5$ & u. po7 & & ranks & & \\
\hline d. po $2<\mathrm{pr} 2$ & & j. po $4<$ pr 4 & p. $\mathrm{p}$ & pr6 & v. po8 & & z. based & n positive 1 & nks \\
\hline e. $p o 2>$ pr2 & & k. po $4>$ pr 4 & q. $\mathrm{p}$ & pr6 & w. po\& & & aa. base & on negative & rank \\
\hline f. $p o 2=$ pr 2 & & 1. po $4=$ pr 4 & r. pc & pr6 & x. po8 & & & & \\
\hline
\end{tabular}

Table 3 shows the ranking based on the pretest and post-test and the statistical test results. Pretest questions are addressed as 'pr' and the question number, e.g. pr1 means 
pretest of question 1. Post-test questions are addressed as 'po' followed with the question number, e.g. po1 means post-test of question 1.

The Wilcoxon signed-ranks test from both assessors indicated that each question's posttest scores were not significantly higher than the pretest scores, as each of the questions had a $\mathrm{p}$ value exceeding 0.01 . This value means that there are no significant differences between teachers' answers in the pretest and post-test. Participants' answers remained consistent even after a ten-day gap between pretest and post-test, where no treatment was given. This statistic report showed that the instrument is reliable to use and the researchers decided not to make any further modifications to the current version of the instrument, as the goal of creating a reliable instrument was achieved.

\section{DISCUSSION}

Previous development of instruments to measure teachers' PCK were created only for certain subjects such for environmental education (Abdullah \& Halim, 2013), science education (Kratz \& Schaal, 2015) and biology education (Jüttner et al., 2012). These instruments are not sufficient to measure teachers' PCK who taught different subjects, such as economy, geography and others. One instrument that could be used to validly and reliably measure teachers' PCK using the same standard is still lacking, and still in need of development. Such a development would be very useful to check teachers' PCK, especially for school management teams to measure the quality of their teachers and even to diagnose their teachers' practice.

This study created an instrument to measure PCK using an action learning framework to answer that challenge. An instrument was created that could measure teachers' PCK regardless of the subject they teach by connecting the PCK concept with teachers' reflective thinking about their teaching practice. This connection was created by using an action learning framework, specifically the WMCLM, where the reflection process is carried out within an existing context, in this case, teachers' practice in the classroom.

The researchers created eight questions that corresponded with each of the eight steps in the WMCLM. These questions provoked teachers to think about their PCK according to an adult learning perspective. The instrument used the definition of PCK from MorineDershimer and Kent's PCK model, which explains the seven knowledge types that teachers need to master. All that knowledge should be externalized by the teacher as they answered questions in the instrument. The questions in the instrument were validated by two experts in education. Meanwhile, the reliability test for the instrument used the Wilcoxon signed-ranking test to analyze the data. The data showed that all of the questions had $\mathrm{p}$ values exceeding 0.01 . This means that all the questions are reliable; hence, the instrument is reliable to use.

This instrument was designed so that teachers could easily explicate their PCK as the result of answering the questions contained in it. PCK is a new concept and there is lack of documentation about it being explored by teachers as practitioners. Hence, a step-bystep thinking process to externalize teachers' PCK is needed, as provided by this instrument. 
Previous research on determining teachers' PCK mostly uses subject-specific questions. According to Kratz and Schaal (2015), an instrument to measure PCK was given in the form of closed-ended, true or false and multiple-choice questions regarding a narrow subject in biology and contextual specific content. A similar type of assessment was developed by Abdullah and Halim (2010), where they created a series of questions on environment-related questions, curriculum, students, teaching strategies and evaluation. On the other hand, Jüttner et al. (2002) created open-ended questions to measure teachers' PCK. However, this instrument was only for biology teachers.

Closed-ended questions such as multiple choice, short answer and yes or no questions, provide little opportunity for teacher participants to demonstrate their PCK (Angelo \& Cross, 1993). This is not an ideal form of assessment considering teachers have to teach a lot of content in various possible situations (Baxter \& Lederman, 1999). Furthermore, PCK not only consists of a series of possible ways to teach (pedagogy) and subject matter (content) but is also constructed by the ability to adapt teaching strategies (such as type of context, content that needs to be taught etc.) with classroom situations (learners' characteristics, misconceptions etc.). To respond to these conditions, the researchers used open-ended questions in this instrument to give an opportunity for teachers to write down their experience accordingly. Open-ended questions encourage freedom for teachers to express about experience that researchers never thought existed before (Angelo \& Cross, 1993). Hence, the assessment process is not limited to 'what' the researchers expects teachers to know but includes how they use any knowledge that constructed PCK and incorporate it as one systematic strategy to face past problems in their classroom.

The strength of this instrument is the ability to make teachers reflect and explicate about their different, unique and specific problems using general questions developed from the WMCLM framework. The researchers designed the wording of the questions in the instrument to be 'general questions', which could allow teachers to start reflecting on their practice regardless of their subject. Such questions allow teachers to answer more freely and true to their context without being limited by the assessment questions. This is unlike previous instruments, which are mostly heavily integrated with the subject matter. Those instruments cannot be used to measure PCK of teachers from different subjects, as mentioned previously.

This is the benefit of using the WMCLM in this instrument. Although action learning was first introduced in the industrial area, it has been used in other fields, such as business and health. Action learning is flexible, because requires its participants to reflect on each individual past experience before learning from it (Revans, 1982). This instrument, which uses action learning as its framework, does not provide contextual problems for them to solve, but it takes teachers back to their own problems, so each of them are guided to face their own problems using the same questions of PCK. Therefore, this study also contributes to the action learning field by demonstrating how action learning could be used to facilitate reflective thinking for teachers.

There are limitations to this study. This research is a part of doctoral research in Indonesia. The main school where the experiment was conducted is a boarding school. 
Hence, the researchers chose another similar boarding school that follows the provincial regulations and national curriculum. Since the teachers from the chosen school follow the same regulations as teachers in regular schools in Indonesia, this instrument is applicable for teachers in regular schools in Indonesia. However, further investigation regarding its use in other contexts is still needed, such as for teachers who taught using different curriculum from other country. Besides that, this instrument also opens an opportunity for other researchers to conduct comparison studies between this instrument and other PCK assessment instruments, which could contribute enormously to PCK research.

\section{CONCLUSION}

This instrument is created to assess teachers' understanding of PCK by helping them to realize their current practice through reflection as guided by the WMCLM steps. Teachers are guided by the WMCLM as an action learning method so that they could connect and reflect on their past practice. This process helps them to think about PCK and make the measuring of PCK possible. As previously shown, each of the questions in this instrument are valid in terms of content and reliable, as proven statistically. They are valid because the researchers have demonstrated that each question is constructed from the WMCLM steps and PCK. This instrument is also reliable, as shown by the Wilcoxon signed-rank test. Each of the questions has a p value exceeding 0.01 ( $p>$ 0.01) which means that the instrument gives consistent results for the same participants who did not undergo any specific treatment, even after ten days.

Previous research, which has also created instruments to measure PCK, created them only for specific subjects. For example, Abdullah and Halim (2010) created an instrument to measure PCK for environmental education, Kratz and Schaal (2015) for science education and Jüttner et al. (2012) for biology education. This study shows that it is possible to measure teacher's PCK for various subjects using the WMCLM framework in the instrument. This is unlike previous research on PCK instrument, which are mostly created only for a specific subject. It opens an opportunity for school to measure all teachers' PCK at the same time regardless their subject. School management could use this instrument to map out teachers' PCK and provide suitable follow up to any meaningful findings regarding teachers' quality, such as providing training and skill development. Since this study involve teachers who taught using Indonesia's national curriculum, this instrument can be used for teachers who taught using the same curriculum. Furthermore, the researchers also recommend for further investigation about the reliability of this assessment for teachers from different context, such as teachers from other country that used different curriculum. A comparison study between this instrument and other PCK instrument is also recommended.

\section{REFERENCES}

Abdullah, SISS \& Halim, L. (2010). Development of instrument measuring the level of teacher's pedagogical content knowledge (PCK) in environmental education. Procedia Social and Behavioural Sciences, 9, 174-178.

Airasian, P. W., \& Miranda, H. (2002). The role of assessment in the revised taxonomy. 
Theory into Practice, 41(4), 249-254.

Anderson, R. S. (1998). Why talk about different ways to grade? The shift from traditional assessment to alternative assessment. New Directions for Teaching and Learning, 74, 5-16.

Angelo, T. A., \& Cross, K. P. (1993). Classroom assessment techniques: A handbook for college teachers. San Francisco: Jossey-Bass Publishers.

Atkins, S., \& Murphy, K. (1993). Reflection: A review of the literature. Journal of Advanced Nursing, 18(8), 1188-1192.

Baxter, J. A., \& Lederman, N. G. (1999). Assessment and measurement of pedagogical content knowledge. In J. Gess-Newsome, \& N. G. Lederman (Eds.), Examining PCK (pp. 147-163). Boston, MA: Kluwer.

Beard, C., \& Wilson, J. P. (2013). Experiential learning: A handbook for education, training and coaching. London: Kogan Page Publisher.

Bloom, B. S. (1956). Taxonomy of educational objectives, handbook I: The cognitive domain. New York: David McKay.

Brix, V. H. (1983). Action learning and control theory. Omega, 11(5), 491-500.

Brook, C., Pedler, M., \& Burgoyne, J. (2012) Some debates and challenges in the literature on action learning: The state of the art since Revans. Human Resource Development International, 15(3), 269-282.

Boud, D. (1993). Experience as the base for learning. H. Edu. Re. \& Dev., 12(1), 33-44.

Carlsen, W., (1999) Domains of teacher knowledge. In J. Gess-Newsome, \& N. G. Lederman, (Eds.). Examining pedagogical Content Knowledge (pp 133-145). Dordrecht: Springer Netherlands.

Chenhall, E. C., \&Chermack, T. J. (2010). Models, definitions, and outcome variables of action learning: A synthesis with implications for HRD. Journal of European Industrial Training, 34, 588-608.

Christiansen, A., Prescott, T., \& Ball, J. (2014). Learning in action: Developing safety improvement capabilities through action learning. Nurse Edu. Today, 34(2), 243-247.

Corder, G. W., \& Foreman, D. I. (2009). Nonparametric statistics for non statisticians. New Jersey: John Wiley \& Sons, Inc.

Dilworth, R. (2010). Explaining traditional action learning: concepts and beliefs. In Boshyk, \& Dilworth (Eds.), Action learning: History and evolution (pp.3-26). London: Palgrave Macmillan.

Forehand, M. (2005). Bloom's taxonomy: Original and revised. In M. Orey (Ed.), Emerging perspectives on learning, teaching and technology. E-Book. Retrieved from https://textbookequity.org/Textbooks/Orey_Emergin_Perspectives_Learning.pdf. 
Fraenkel, J. R., Wallen, N. E., \& Hyun, H. H. (2012). How to design and evaluate research in education. New York: Mc Graw Hill.

Gess-Newsome, J., Taylor, J. A., Carlson, J., Gardner, A. L., Wilson, C. D., \& Stuhlsatz, M. A. M. (2019). Teacher pedagogical content knowledge, practice, and student achievement. International Journal of Science Education, 41(7), 944-963. doi: 10.1080/09500693.2016.1265158.

Gess-Newsome, J. (1999). Pedagogical content knowledge: an introduction and orientation. examining pedagogical content knowledge. In J. Gess-Newsome, \& N. G. Lederman, (Eds.), Examining pedagogical content knowledge, (pp. 3-20). Dordrecht: Springer Netherlands.

Griffiths, T., \& Guile, D. (2001). Learning through work experience. Journal of Education and Work, 14(1), 113-131.

Grossman, P. L. (1990). The making of a teacher: Teacher knowledge and teacher education. New York, NY: Teachers College Press.

Harr, N., Eichler, A., \& Renkl, A. (2014). Integrating pedagogical content knowledge and pedagogical/psychological knowledge in mathematics. Frontiers in Psychology, 5, 924. doi: $10.3389 /$ fpsyg.2014.00924.

Jay, J. K., \& Johnson, K. L. (2002). Capturing complexity: A typology of reflective practice for teacher education. Teaching and Teacher Education, 18, 73-85.

Jüttner, M., \& Neuhaus, B. (2012). Development of items for a pedagogical content knowledge test based on empirical analysis of pupils' errors. International Journal of Science Education, 34(7), 1125-1143.

Jin, H., Shin, H., Johnson, M. E., Kim, J., \& Anderson, C. W. (2015) Developing learning progression-based teacher knowledge measures. Journal of Research in Science Teaching, 52(9), 1269-1295.

Kolb, D. A. (1984). Experiential learning: Experience as the source of learning and development. Upper Saddle River, NJ: Pearson.

Kratz, J., \& Schaal, S. (2015). Measuring PCK - discussing the assessment of PCKrelated achievement in science teacher training. Procedia - Social and Behavioral Sciences, 191, 1552-1559.

Magnusson, S., Krajcik, J., \& Borko, H. (1999). Nature, sources and development of pedagogical content knowledge for science teaching. In J. Gess-Newsome, \& N. G. Lederman (Eds.), Examining pedagogical content knowledge (pp. 95-132). Dordrecht, Netherlands: Kluwer Academic.

Mezirow, J. (1997). Transformative learning: Theory to practice. New Directions for Adult \& Continuing Education, 74, 5-12 
Morine-Dershimer, G., \& Kent, T. (1999). The complex nature and sources of teachers' pedagogical knowledge. In J. Gess-Newsome, \& N. G. Lederman (Eds), Examining pedagogical content knowledge (pp. 21-50). Dordrecht: Springer Netherlands.

National Research Council. (2001). Knowing what students know: The science and design of educational assessment. Washington, DC: The National Academies Press.

O'Neil, J., \& Marsick, V. J. (2007). Understanding action learning. New York: AMACOM.

O’Donoghue, C. (2011). Franchisees in crisis: Using action learning to self-organise. Action Learning. Research and Practice, 8(3), 255-259.

OECD. (2014). PISA 2012 results in focus: What 15-years-olds know and what they can do with what they know. Paris: OECD. Retrieved from https://www.oecd.org/pisa/keyfindings/pisa-2012-results-overview.pdf.

Povozhaev, L. (2014). Essay-A metaphor: Writing to show thinking. In T. Roeder, \& R. Gatto (Eds.), Critical expressivist: theory and practice in the composition classroom, (pp. 93-103). Fort Collins, Colorado: The WAC Clearinghouse and Parlor Press.

Ratminingsih, N. M., Padmadewi, N. N., \& Artini, L. P. (2017). Incorporating self and peer assessment in reflective teaching practices. Int. J. of Instruction, 10(4), 165-184.

Revans, R.W. (1982) What is action learning? J. of Manag. Development, 1(3), 64-75.

Roessger, K. M. (2012). Toward an interdisciplinary perspective. Adult Education Quarterly, 62(4), 371-392.

Rosser, E. (2016). Work-based learning using action learning sets. British Journal of Nursing, 25(19), 1075.

Shulman, L. S. (1986). Those who understand: Knowledge growth in teaching. Educational Researchers, 15(2), 4-14.

Shulman, L. S. (1987). Knowledge and teaching. Harvard Edu. Review, 57(1), 1-22.

Smyth, J. (1989). Developing and sustaining critical reflection in teacher education. Journal of Teacher Education, 40(2), 2-9.

Stevens, D. D., \& Levi, A. J. (2005). Introduction to rubrics. Sterling, VA: Stylus.

Tusting, K., \& Barton, D. (2003). Models of adult learning: A Literature Review. Lancaster: NRDC

Watkins, K. E., \& Marsick, V. J. (1993). Sculpting the learning organization: Lessons in the art and science of systemic change. San Francisco: Jossey-Bass. 